Article

\title{
Governing Climate Finance in Fiji: Barriers, Complexity and Interconnectedness
}

\author{
Kirsty Anantharajah
}

School of Regulation and Global Governance (RegNet) College of Asia and the Pacific, Australian National University, Canberra 0200, Australia; Kirsty.Anantharajah@anu.edu.au

Received: 31 May 2019; Accepted: 13 June 2019; Published: 21 June 2019

\begin{abstract}
Pacific Island Countries are most vulnerable to the disastrous impacts of climate change; they also, however, manifest some of the most ambitious international climate commitments. Fiji, for one, has sought to respond to the escalating threat by setting highly ambitious climate mitigation targets, specifically in the energy sector. Finance is key to the realization of these goals: governors must attract and meaningfully invest vast sums to support these mitigation targets. This study, through qualitative, empirical, and inductive methods, found that a complex landscape of barriers stood between governors and the translation of finance into positive climate outcomes. The study categorized barriers into four different planes of deepening entrenchment: Level One barriers are the most tractable, whereas Level Four barriers are immovable. The study found that these barriers interrelate between levels, creating complex chains of entrenchment. A superficially tractable issue may be rendered less so by being rooted in a more entrenched issue. Empirically, this paper delineates the complex landscape of challenges, or 'context', that Fijian climate governors must understand in order to deliver effective governance solutions. Beyond this, this research offers a framework of broader application through which climate governors may conceptualize complex barriers.
\end{abstract}

Keywords: climate finance; Pacific Small Island Developing States (PSIDS); Fiji; governance; policy; development; barriers; renewable energy

\section{Introduction}

The 2018 Intergovernmental Panel on Climate Change (IPCC) report foreshadowed the potentially cataclysmic consequences of untrammeled climate change. In the Pacific, however, these consequences have already been felt with extreme weather events, loss, destruction, threatened food security, sinking islands and displacement. The need to mitigate and adapt to climate change is thus, unsurprisingly, at the core of Pacific development agendas.

Pacific Small Island Developing States (PSIDS) contribute negligibly to global emissions. Yet, under the Paris Agreement, PSIDS have submitted highly ambitious Nationally Determined Contributions (NDCs); Fiji, for one, has conditionally committed to generating $100 \%$ of its electricity from renewables and to curbing overall emissions from the energy sector by $30 \%$ by 2030 . The symbolic significance of meeting (or going close to meeting) these targets is immense, notwithstanding Fiji's minimal contribution to climate change. Specifically, these targets are a means by which Fiji is endeavoring to influence global behavior. As articulated by Fiji's Prime Minister, Frank Bainimarama, "Why [have such ambitious mitigation goals]? Particularly when we contribute so little to the warming that threatens our planet? Because we are determined to do what we are asking others to do and to lead by example." [1].

Achieving these goals will also have a powerful impact on Fiji's development domestically. Firstly, increasing renewable energy (RE) penetration in Fiji is both a means of mitigation and adaptation. Mobilizing towards Fiji's NDCs will expand reliable energy access to remote communities, increasing 
their resilience and performing an important adaptive function. A transition to a greater share of renewables in generation capacity may also increase national economic resilience. Fiji imports all its diesel, so transitioning to clean energy (Sustainable Development Goals 7 and 13) will release the nation from fossil fuel dependence and, thus, its vulnerability to external oil price shocks. Finally, the pursuit of these goals could, and indeed should, enliven local industry, innovation and a local private sector (Sustainable Development Goals 8 and 9).

Realizing these ambitious development goals will, however, require unprecedented levels of finance to rapidly be mobilized and channeled into sustainable projects. Meeting national emissions reduction targets in the energy sector alone in Fiji, the central focus of this paper, will require an estimated US\$ 2.97 billion between 2017-2030 [2], an amount will which need to flow from both private and public sources.

The financing challenge facing Fiji and the region, however, is not simply one of mobilizing this level of funding (though that is an immense challenge in its own right); rather, it encompasses the need for a pipeline of sustainable projects to invest in, as well as the assurance of the ongoing longevity of the projects. Yet all too often, accounts of the financing gap tacitly assume that these 'secondary' conditions are unproblematic, ignoring the enormous challenges they present in national and subnational contexts.

In response to this status quo, this study interrogates: what are the barriers to mobilizing, investing and absorbing climate finance, and reaping subsequent climate outcomes in Fiji?

This paper engages with this question, by 'deep diving' into the challenge of financing Fiji's climate mitigation targets in the energy sector, focusing particularly on the electricity subsector. Given the level of finance needed, this will necessarily focus largely on the mobilization of mixed and private sources of finance, and the inclusion of private actors. The analysis will be targeted at the national and subnational level, or put differently, at the 'many hands of the state' level [3] which encompasses the diverse range of governing actors.

This paper will be organized as follows. First, the methodology used in this study will be outlined. Second, the analytical context and the framework developed will be introduced. The findings and discussion will follow. Here, the paper will explore the barriers to climate finance in Fiji on four levels, ascending on the basis of entrenchment. This paper explores the complexity arising from the interlinking of barriers between levels, demonstrating how relationships between superficially tractable barriers could be rendered less so by being rooted in a less tractable challenge. At this point, we will begin to see barriers as part of complex chains, and opposed to contained barriers that can be resolved in isolation. This conceptual approach, though developed from the Fijian context, has great potential in analyzing complex climate governance challenges in other Pacific nations, small island developing states and developing nations.

\section{Methodology}

This study is based primarily on empirical data informed by three months of fieldwork conducted in Suva, Fiji in conjunction with policy reports, existing academic literature, roadmaps and briefs. Interviews with consultants and other international stakeholders were also conducted in Canberra and Sydney, Australia. The Pacific methodology of Talanoa was used where possible [4,5]. Talanoa is a cultural discursive practice recognized in many Pacific nations. It was popularized as research method in the Pacific following its application as a dispute resolution tactic by Sitiveni Halapua in the aftermath of Fiji's 2000 coup [4]. Whilst there are many different understandings of Talanoa, including its literal translation of 'talking about nothing in particular,' and 'offloading', it arguably has a consistent underpinning: a shared emotionality and a strong sense of empathy [4]. Taking the time to build trust and interpersonal relationships are a precursor to 'emotionally embedded reciprocal exchange between researcher and participants' [4]. This prioritizes empathetic, unhurried communication that is respectful of context. 
The research reported is qualitative in nature, and is aimed at the production of grounded theory [6]. It aims not to test a theory, but rather, to enable an in-depth and rich understanding of the context that governors in Fiji must navigate. Thus, the inductive processes involved in grounded theory were deemed suitable. It is also compatible with Talanoa, which requires researchers to approach questions openly, without a desire to test a particular theory.

The data collection involved some 40 semi-structured interviews and Talanoa dialogues with various governors including multilateral developmental organizations, bilateral aid partners, regional organizations, national and provincial government, financial institutions, private consultants, NGOs, and local private companies who are involved in sustainable development and renewable energy in Fiji.

In terms of case selection, there are many reasons to focus on Fiji, not least that it displays the most promise amongst PSIDS in terms of transitioning to a low-carbon economy: it has ample renewable energy resource availability; it has some of the highest electrification rates in the region; its electricity utility, recently corporatized, is one of the region's most functional and best performing; it boasts one of the most active private sectors with key, highly regarded local renewable energy companies which operate regionally; and Fiji's government has acted as a regional leader in climate change diplomacy and demonstrates clear vision towards ambitious climate change mitigation targets and adaptation outcomes. The latter point has manifested in Fiji taking on the Presidency of COP23; the government's issuance of a Green Bond valued at 50 million USD, the first developing country to do so; and Fiji's Development Bank achieved accreditation with the Green Climate Fund, again a regional first.

Yet, beneath its highly visible successes, Fiji, like others in the region faces deep seated and complex challenges that, without attention and targeted intervention, have the potential to stymy the financing and realisation of the country's green growth aspirations [7].

\section{Analytical Context and Framework}

The concept of climate finance (and the broader green finance) has gained traction globally over the last decade, manifest in the increasing volume of high-level reports of various international organisation and development agencies [8-12]. Much of this discussion, however, focuses on the availability or mobilization of climate finance, neglecting, for the most part, a meaningful engagement with more national and subnational issues of absorbing climate finance and steering toward climate outcomes. Another asymmetry in this body of reports is that, when national level analysis occurs, great emphasis is placed on a certain type of barrier: misaligned policy [13]. This focus, also manifest in roadmaps produced in Fiji, often fails to adequately address more deep-seated barriers.

Climate finance for renewable energy in Fiji remains an understudied area; Atteridge and Canales [14], for example, note a dearth of synthesized data on climate finance in the Pacific region. Whilst there is still limited literature specifically on climate finance in Fiji, some analyses of the discreet elements that pertain to it have been published. There is, for example, a growing body of high-quality studies surrounding renewable energy in Fiji. Some of this contributes technical analysis and financial modeling (see [15-17]). However, the challenge of climate finance stretches beyond the technical. As Michalena and Hills [18] point out: "renewable energy governance might block the technically feasible" (see also [19]). The literature has reflected this by engaging with important aspects of renewable energy governance in Fiji and the region [20-23].

The academic literature does, however, manifest critical gaps. The literature has grappled with many of the barriers or lacunae in conditions enabling climate aligned development, specifically renewable energy uptake in PSIDS [23-25]. However there is yet to be a holistic examination of the complex landscape of challenges in particular, one that takes into account planes of entrenchment of individual barriers and how they interact with other barriers. A 2014 study by Eisenack et al., on climate change adaptation identified a similar gap in the adaptation literature; that is, a lack of deep engagement with barriers [26]. Eisenack et al.'s study goes on to identify three-pronged research agenda: identifying, explaining and overcoming barriers to adaptation. Based on the gaps identified 
in the production of knowledge surrounding climate finance in Fiji, it is evident that this agenda is pressing here also.

This study aims to translate and action this agenda in the study of climate finance, particularly within the context of achieving renewable energy targets in the Fijian energy sector. It contributes an identification and explanation of complex barriers to mobilizing, investing and absorbing climate finance, and reaping subsequent climate outcomes in Fiji.

Why focus on barriers and not governance solutions? This question harks back to the wisdom shared by provincial-level governors for this study. They saw a root of governance dysfunction as the failure to do 'ground work,' and engage with local context. In grappling with barriers, this paper contributes that ground work. Empirically engaging with and representing this complexity, the contribution made by this paper, lays the vital groundwork for effective governance interventions. Without clearly identifying and analyzing barriers and the interlinkages between them, it is unlikely that credible policy can be developed through which they might best be overcome, managed, reduced or avoided [26].

The theoretical contribution of this paper is to propose a new framework of understanding barriers to climate finance. This analysis involves two novel approaches to the climate financing challenge in the Pacific. First, based on substantial empirical work, barriers are classified by considerations of entrenchment: are they capable of resolution? Are they fixed limits? Second, the relationships between barriers on different levels will be explored. Doing so, it will be argued, will encourage more holistic understandings of the climate financing challenges, and result in more grounded and well adapted governance approaches.

Four 'levels' of barriers to financing sustainable development will be explored. It will be argued that the 'entrenchment' of the barriers in each level increases with each ascending level. Level One (L1) involves barriers posed by lacunae in the regulatory and policy framework, and gaps in strategic planning. The second level (L2) involves various underlying conditions that stymy the financing, development and sustainability of projects. These include: an underdeveloped private sector, limits to financial opportunity, limited opportunity for private participation in the energy markets and limited bureaucratic capacity. Amelioration of these barriers requires mid to long term intervention and support for resolution. The third level (L3) involves barriers presented by powerful international forces operating in Fiji: the donor community. Level Four (L4) barriers are immovable and intrinsic aspects of Fiji's circumstances. They include: geography, distance and scale; land and custom; and the social embeddedness of 'deals.' These matters cannot be 'resolved' and rather, must be understood and adapted to.

This paper then explores the complexity arising from the interlinking of barriers between levels, demonstrating how relationships between superficially tractable barriers could be rendered less so by being rooted in a less tractable challenge (see Figure 1). Here, we begin to see barriers as part of complex chains and opposed to contained barriers that can be resolved in isolation. 


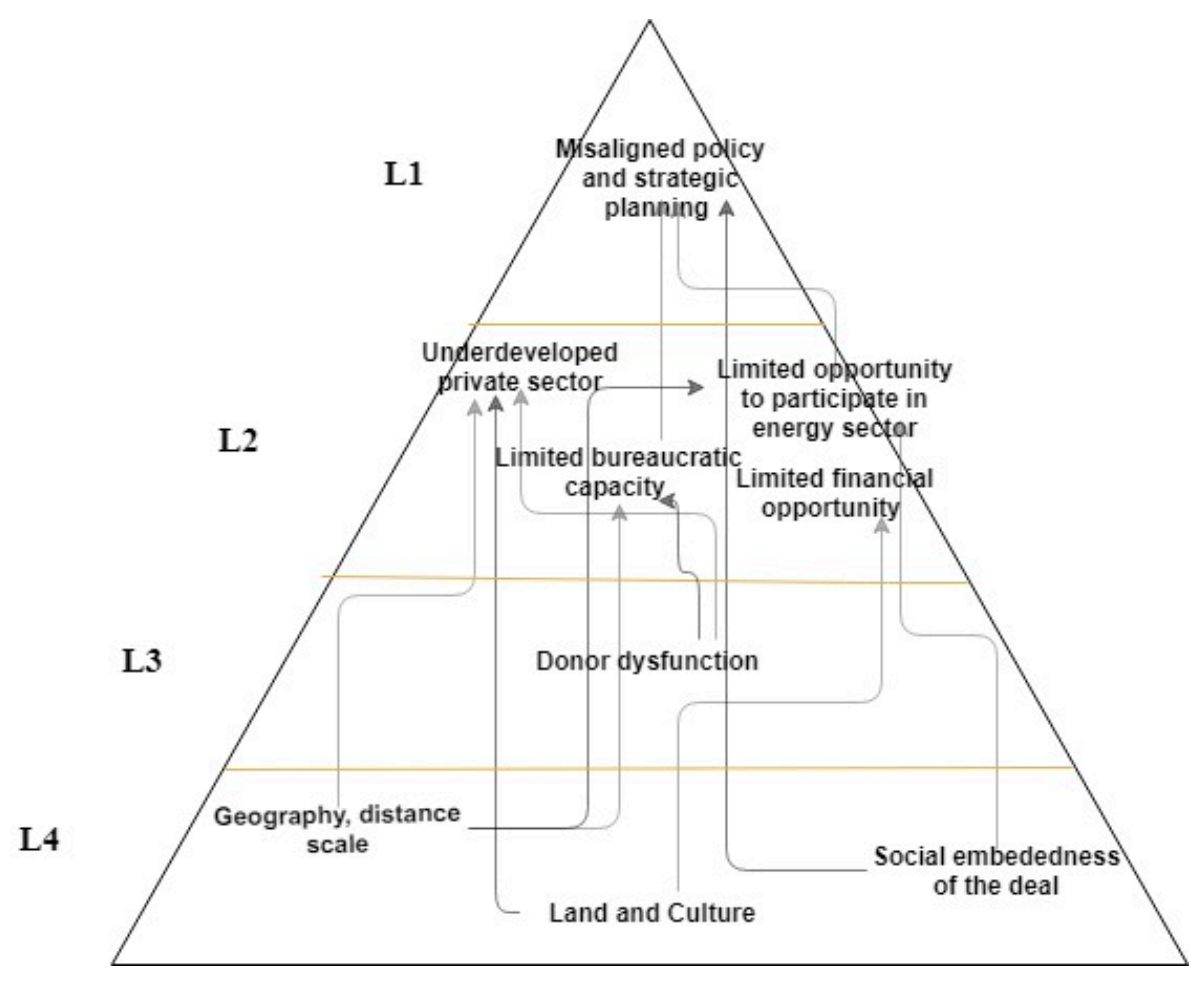

Figure 1. Author's work.

\section{Findings and Discussion}

\subsection{Level 1: Superficially Tractable Challenges}

Investment and subsequent deployment of renewable energy relies on a supportive policy environment. Timilsina and Shah assert large-scale deployment of renewable energy, including the kind Fiji requires to meet its targets, is policy driven [22]. A lack of supportive policy and regulatory frameworks in Fiji was cited as a significant barrier in interviews across stakeholder groups, a barrier salient across the region [25]. This barrier is categorized as L1 because they are superficially tractable: they are capable, theoretically at least, of resolution by the creation and realignment of policy. Indeed, much of the necessary reforms have already been 'road-mapped' by Fiji's development community. Yet, as will be argued in the second part of the study, the chasm between policy proposals and 'on the ground' implementation, and the prevalent lethargy at the latter level, suggest that L1 challenges are much more complex than immediately apparent.

\subsubsection{Strategic Planning}

Fiji has set highly ambitious green goals; under the Paris Agreement, Fiji submitted a NDC conditionally committing to generating $100 \%$ of its electricity from renewables, and curbing overall emissions from the energy sector by $30 \%$ by 2030 . The pathways to achieving these goals, however, have been less clear. One government respondent noted that bureaucracies were under significant time pressures in submitting their NDCs, which resulted in Fiji announcing these goals prior to engaging in strategic planning. The Global Green Growth Institute (GGGI) in conjunction with the Ministry of Economy released a NDC Roadmap in 2018, which aimed to bridge the gap between commitments and outcomes. As will be explored in the following section, the translation of these high level NDCS beyond 'road mapping' has lagged. 
4.1.2. Policy Alignment towards Realization of Energy Sector NDCs: Failure to Encourage Renewable Energy Generation or IPP Participation

Fiji's ability to mitigate its energy sector emissions will depend on its capacity to rapidly scale up renewable energy generation. This invariably requires private sector participation due to the limited fiscal and technical capacity of the state and the electricity utility to invest in new, clean generation. The need to rapidly develop renewable capacity and subsequently, to involve independent power producers (IPPs) in generation have been articulated both in high-level statements by the Fijian government as well as in the NDC Roadmap. These ambitions, however, are not reflected in Fiji's legislative and regulatory framework, within which numerous lacunae frustrate the development of renewables and private participation.

Interviews and data supplied by respondents reveal various legislation and regulatory gaps, with some of the holes that have been identified being remarkably large. The 2017 Electricity Act (still not in force at the time of writing), for example, does not support or incentivize renewable energy, being, as one participant put it, 'technology neutral.' (donor agency respondent). This is surprising as the Act was developed around the same time as Fiji was committing to $100 \%$ renewable energy generation at COP23, yet the Act's 'neutrality,' actually operates to entrench the status quo and is fundamentally at odds with Fiji's ambitions.

The Act does, however, contemplate the provision of independent regulation rather than self-regulation, which is an important shift from the status quo of Energy Fiji Limited (EFL- FEA before corporatization) engaging entirely in the latter. While it is indeed a positive that the energy sector will, in principle, gain an external regulator, the Act is silent on the nature of this regulator. The issue of tariff setting was raised repeatedly by stakeholders. Prices in Fiji are set at $33 \mathrm{c} / \mathrm{KWh}$ (ex VAT); a uniform tariff that does not represent the full cost of generation, with the result that EFL lacks the capital necessary to reinvest in new generation. Respondents noted that the price setting in the electricity sector is politically charged. Whilst there have been minimal changes over the past several decades, 2010 saw an increase in tariff to be largely reflective of costs [21]; however, three years later, the government reduced tariffs by $5 \%$ [15]. Previous studies have also drawn the independence, and capabilities of this Commission into question [21] (p. 709), [27]. Respondents in the present study also expressed concern that this organization lacks the requisite skill and expertise to perform broader regulatory functions within the energy market.

This regulatory challenge is exacerbated by the fact that there is little in the Act to guide the new regulator in steering Fiji's energy markets towards the country's high-level green goals; renewable energy is neither defined or incentivized, and Fiji's NDC's are absent from the Act's objectives (technical respondent). The lack of legislative guidance regarding incentivizing renewable energy does little to compel the Regulator to ameliorate the status quo of fossil fuel dependence. The lack of incentives, such as an attractive feed in tariff and net metering was raised in interviews by a range of stakeholders, though frustration was particularly pronounced in the private sector. Indeed, in remaining silent on renewables in a context of an economy tilted in favor of diesel generation, the 'technology neutral' Act can more accurately be described as an instrument in danger of entrenching fossil fuel dependence.

A key gap in the enabling environment is the lack of supports for engaging actors beyond the utility in renewable power production, and specifically Independent Power Producers (IPPs). The utility itself does not have the capacity, either in the sense of budget or technical capacity, to invest and operate on the scale of renewable power generation required to meet Fiji's NDCs. Currently, while EFL's generation mix has a significant proportion of hydropower, it has extremely limited grid connected solar. Thus whether or not Fiji has the potential to achieve its green goals depends heavily on its ability to include renewable IPPs in power generation. Thus far, there are only two IPPs operating in Fiji, and one is in fact state owned [28]. This speaks to the adverse climate for private participation in generation. Private sector respondents cited a lack of policy supports such as standardized Power Purchase as barriers to their participation. One official (government respondent) noted that the new Act does little to encourage inclusion. 
Multiple other lacunae in Fiji's legal and regulatory framework have been identified in a variety of reports and roadmaps [24,29-32]. Yet these issues persist. This is suggestive of another theme that emerged from stakeholder interviews: consultants and private sector actors expressed deep frustration and cynicism about the state's ability to implement reform. For example, there have been numerous road-mapping exercises suggesting reform towards a more enabling environment, yet these have overwhelmingly not been actioned; these exercises are then reproduced, as will be discussed in the next section, despite the failure of their predecessors to make an impact. The glut of roadmaps and reports that 'grow dusty on ministerial shelves' (development community respondent) is a manifestation of chronic and serious implementation dysfunction.

\subsection{Level 2: Reasonably Entrenched Challenges}

The barriers discussed here are 'reasonably entrenched,' that is, they are largely incapable of short-term solution, and will require medium to long-term support and intervention for their amelioration. L2 'reasonably entrenched' challenges to financing climate change mitigation include: an underdeveloped private sector; limited financial opportunity; limited opportunity to participate in the energy market; and limited state capacity.

\subsubsection{Underdeveloped Local Private Sector}

Fiji acknowledges that it will make little progress towards its green goals without the mobilization of its local private sector, especially its small to medium-sized enterprises (SMEs) [33]. Yet such mobilization is a considerable challenge. One of the most significant barriers to investment in Fiji is a lack of deal flow, or in other words the existence of projects or business opportunities to invest in.

The importance of a 'local' as opposed to imported expertise is another important distinction. Various stakeholders in this study emphasized the need for the workforce to be local; and asserted that a profound understanding of Pacific and Fijian conditions is key to the success of projects. One participant noted that consultants with limited Pacific experience, despite palpable good intentions, often deliver poor results: "they don't understand the environment-if you haven't lived through a pacific cyclone you don't understand cyclones." (former energy sector governor discussing the resilience of solar infrastructure). Furthermore, the concern articulated by Cole and Banks that certain renewable programs will replace fossil fuel dependency with dependence on external technical assistance can be assuaged if this capacity could be sourced locally [34].

In Fiji, SMEs comprise a large portion of the private sector. This remains the case with the renewable energy industry, and SMEs operating in this sector have both modest human resources and assets. Yet such companies have had a remarkably large impact in Fiji, and have an operational history of taking on and successfully completing very large projects, suggesting the need to harness such companies more fully, and allowing for more such enterprises to grow into maturity, which in turn implies identifying and overcoming barriers to their growth.

The empirical research found that the overwhelming barrier to the growth of renewable energy SMEs was limited access to finance. Most SMEs are reliant on banks for finance; and difficulties in securing bank loans was consistently reported by private sector interviewees. Notwithstanding banks in Fiji having high liquidity, they have been described by a wide spectrum of stakeholders as risk averse and lacking understanding about renewable energy economics and business. This is manifest in an unavailability of loans and crippling lending terms.

Another area of dysfunction reported by stakeholders concerned collateral requirements of commercial banks, required in the traditional yet ill-adapted form of land. Requiring this form of collateral is particularly problematic in Fiji for several reasons. Firstly, most SMEs would not own their own premises, especially when starting out; thus their inability to provide traditional collateral renders them ineligible for financing. Beyond this, in Fiji most land is customarily owned (to be discussed in L4) and thus not well adapted to being put up as collateral, as the rights to customarily land are inalienable. Yet commercial banks have showed little flexibility in their preference for land as collateral. 
For some Fijian companies, this has meant that management has had to put their own homes up as security in order to obtain the working capital to complete a project.

The findings of the present study join others $[23,33]$ in identifying the development of a local, green private sector as a vital prerequisite to Fiji and PSIDS generally achieving their green energy goals. Indeed, some scholars go so far as to assert, "one of the most pressing regional issues is to strengthen the involvement of the private sector in RE penetration" $[23,33]$. Enhancing access to finance for SMEs is a crucial step.

\subsubsection{Limits to Financial Opportunity}

A closely related issue is the limits to financial opportunity. The financial landscape of Fiji, though one of the most sophisticated in the Pacific, is not prima facie well placed to support Fiji's sustainable development needs in general and those of climate finance in particular. The space is dominated by the commercial banking sector, followed by the Fiji National Provident Fund (FNPF). Local green energy companies are primarily reliant on the former for finance which, as we have previously established, has yielded poor results. Moreover, Fiji's capital markets are small, there are few listed companies on the South Pacific Stock Exchange, and there is no corporate bond market: "the lack of capital markets are things we are really struggling with. Right now there is no infrastructure," as stated by one regulator. The result of the above is that there are limited opportunities to access climate finance and as a result, to translate the 'ring of wealth around the Pacific,' into positive climate outcomes in Fiji (financial sector respondent).

The launch of Fiji's Green Bond valued at 50million USD, however, was one such opportunity. This successful financial innovation brought in diverse domestic and foreign investors. Fiji's green bond was oversubscribed more than twice over which is testament to potential investment appetite, subject to the right financing vehicle and opportunity. Whether such a mechanism can continue to be replicated to respond to increasing investor demand is less certain. As another government official noted: "Fiji's green bonds were global news. But we need to be mindful of the fiscal side of things; bonds are after all debt instruments. We have essentially got sovereign debt, which is not sustainable."

Building the confidence and infrastructure for a commercial bond market might be one way toward more sustainable (in both the economic and environmental sense) finance; however, this is a medium to long-term aspiration. At present, however, it is clear that more must be done to link investors with sustainable opportunities, and green companies and projects with finance.

\subsubsection{Limited Energy Market Opportunity}

Fiji's population, and therefore its customer base, is small; thus the size of the commercial opportunity of renewable energy projects to potential developers is also limited. Beyond this, the particular landscape of the energy market presents further obstacles to both renewable energy penetration and private participation. Participants in this study identified various elements of an 'ideal' regulatory and operative model. These elements were broadly consistent with 'second generation reform,' as outlined by Dornan, which has three objectives: firstly, that retail electricity prices reflect the cost of supply; secondly, that feed in tariffs are sufficiently high to attract IPPs; and finally, that regulatory mechanisms incentivize private engagement with electrification [35].

Conversely, the barriers to increased penetration of clean energy in Fiji's generation described by participants ultimately reflect a failure of these second wave reforms. The tariff dysfunction, noted in L1, is one such failure. Indeed, the consequential fiscal constraints of EFL, which preclude them from investing in new renewable generation capacity, intensifies the need to include third parties to achieve Fiji's NDCs. Moving to the second element, Fiji's policymakers have expressed the intent of steering their energy sector towards the 'monopsony' model, whereby IPPs sell power to a dominant utility that is responsible for most power generation and all transmission, distribution and retail. EFL however, is more accurately described as definitionally lying somewhere between a monopoly and a monopsony. Dornan citing Gatwick and Eberhard describes this operational and regulatory grey area, present in 
many developing countries, as 'a confused and contested policy and institutional space that arises from the fact that the incumbent state-owned utility remains intact and dominant, but where IPPs are also invited into the market, often with less than enthusiastic support from the incumbent.' [35]. Indeed, the 2017 Electricity Act which attempts to corporatize EFL and attract IPPs is confused in the later objective, as noted in L1. As noted by one consultant "FEA [EFL] is difficult and are often unwilling to work with IPPs because they essentially want to control the type of contract. That's why the PPA standardizations aren't being implemented. They put huge storage requirements in which makes the feasibility for IPPs low". Furthermore, tariffs offered to IPPs by EFL, negotiated on a case-by-case basis have been too low to make generation a commercially viable option [23]. This is where the lack of transparency is particularly problematic. Real cost of generation for EFL, according to one participant, is not made transparent and thus potential IPPs must navigate this relationship without highly relevant market information. Further, the general lack of reverse auctions in EFL means that IPPs cannot use successful or unsuccessful bids as benchmarks or pricing guidelines.

Empirical findings showed that EFL, partly due to the fiscal reasons stated above and demonstrated by the opposition it has manifested to IPPs, at the time of writing could be described as ambivalent towards renewables. For Fiji to transition towards a sustainable economy, EFL's buy-in is paramount. The influence and power wielded by EFL in determining Fiji's green goals was a recurrent acknowledgement in interviews (the social conditions which protect this influence will be further explored in L4). Despite this, EFL's hesitance towards renewables is often oversimplified and their internal challenges are overlooked. The primary research grounded a more nuanced understanding of EFL's concerns with renewables; interviews broadly revealed four sources of this hesitance.

Firstly, some participants assert that participants suggest that EFL was not particularly well consulted in the process of developing these ambitious targets despite the fact that they monopolize the sector which requires the most substantial reform if Fiji is to achieve its NDCs. The second source of EFL's uncertainty is its lack of technical capacity; its staff has little experience in solar energy and reviewing tenders which could engage IPPs. As articulated by one respondent (donor organisation), "No one is making the case 'what's in it for the utilities.' You have to show them what's in it. Nobody spoke to the utility about retraining staff".

Thirdly, there is an element of 'technology-ideology' in EFL's decision-making processes. EFL having extensive experience with both hydro and diesel generation have a clear preference for 24/7 generation methods. Solar, though being easily the most feasible and financeable source of renewable energy in Fiji [36] is stochastic in nature [23] and this is a significant barrier for EFL. Though again, this stems from limited understanding about how to manage intermittent power in the network, in the past it has led to an almost ideological rejection of solar as it is not '24/7.' As noted by one respondent, '[EFL] want to guarantee $24 \mathrm{~h}$ power from solar. They are old fashion and are used to hydro, they are not interested in adapting' (former energy official). This is reflected in rates offered to IPPs which are only applicable to those which can sell power to grid "24/7/365" [28]. Renewable energy initiatives thus far have been in their terms, geared towards hydro. This is problematic, as diverse mix of renewable energy sources must be deployed to meet growing demand and avoid greater diesel dependence. Prasad and Raturi found that without implementing further energy efficiency methods, to meet demand of 2040 with renewables the following mix will be needed: $210 \mathrm{MW}$ of biomass, $186 \mathrm{MW}$ of Solar PV, $181 \mathrm{MW}$ of hydro, $81 \mathrm{MW}$ of wind and $6 \mathrm{MW}$ of geothermal [28].

The conservative and risk averse culture within EFL is the fourth theme revealed in interviews and is indicative of a regional trend [23]. Its rigidly top-down internal management was also noted; to quote one former energy sector governor, "management runs EFL like a 1960s style utility." EFL's resistance to renewable generation and the bona fide inclusion of IPPs essentially turns on the inclinations of top tier management, in tandem with an extreme risk aversion that is best understood within the context of Pacific utilities. EFL is the most successful utility, with most others frequently operating at a loss. Thus, its conservative modus operandi has served it well in terms of running a profit-making utility. Though not being beholden to fluctuating oil prices would mean greater energy security for Fiji and a greater 
level of fiscal certainty, for the reasons stipulated above, EFL perceives this not as opportunity, but almost exclusively in terms of risk.

These findings join other studies which characterize institutional cultures of electrical utilities across the globe. Sovacool, for example explored utilities recalcitrance to 'intermittent' renewables in the United States of America, and found that utility and operator objections to [renewables] may be less about technical limitations and more about tradition, familiarity, and arranging social and political order [37] (p. 295).

\subsubsection{Limited State Capacity}

The importance of functioning institutions in renewable energy deployment is established in the literature [22,24]. Overstretched government capacity in PSIDS is a well-documented challenge to sustainable development; indeed, some Pacific energy offices comprise only one or two individuals [24]. The issue of limited bureaucratic capacity is, however, more complex and nuanced than human resource strictures. Indeed, while Fiji has greater human resources in government than most of its neighbours, limited bureaucratic capacity was one of most represented themes in the primary research. Interviews revealed that the limited capacity of Fiji's bureaucracy to manage, absorb, spend and account for public climate finance as well as the state's capacity to implement and enact the requisite reforms are significant barriers to the realization of Fiji's development goals. The empirical findings highlighted the following elements of limited government capacity.

The first challenge is that the limits in government capacity have negative outcomes for creating a business-friendly climate of accountability and transparency. Fiji's Independent Commission Against Corruption (FICAC), for example, receives some 10,000 reports of corruption, mismanagement or abuse of power per year; but FICAC only has the capacity to respond to around $5 \%$, and so barely getting below the surface of accountability and corruption challenges [38]. Issues of transparency and accountability have been significant barriers to investment in the nation, as indicated by Fiji's Doing Business ranking.

Closely related, the second challenge is the ability of the state to absorb and spend climate finance that it receives from external sources; indeed some report that availability of finance significantly outweighs the state's spending capabilities. "People think that the issue is money-it's not. The money and financing is there. The issue is accessing it and spending it." (respondent from donor organisation making a regional generalization.)

The third challenge was that there are signs that skills and confidence to perform traditional bureaucratic functions are in decline. For one, interviewees noted that data, the bedrock for successful policy design, is being collected less frequently. A loss of institutional knowledge and analytical capabilities within certain government departments has also occurred; for multifaceted reasons which include the use of external consultants and the merging of departments. Commonly too, skill and knowledge is concentrated in the highest echelons of the department, with little confidence or capability within middle and lower bureaucratic rungs, notwithstanding that many decisions are taken at the latter levels. The lack of systematic training entrenches this status quo.

The fourth theme evident in the interviews was inconsistent collaboration between departments and with private sector actors. Collaboration between the private sector and government is at best, ad hoc. This has manifested in a disconnect: while the state cites private sector collaboration as an important goal, policy makers and regulators have displayed a lack of understanding about the actual challenges that face this sector.

\subsection{Level 3: International Forces}

\section{Aid Dependence}

The donor sector has had a profound impact on the governance of sustainable development and its financing in Fiji. The nature of donor engagement, whilst channeling much needed support, 
adds a level of complexity to the development challenge, and can in certain ways be dysfunctional. The primary research revealed three types of donor dysfunction.

Firstly, interviewees noted an inundation of roadmaps and scoping studies in Fiji, which often do not lead to implementation. The overproduction of this type of developmental support has resulted in much frustration on the part of those contracted to develop roadmaps as well as their recipients, borne of the fact that these instruments are so frequently ignored once they have been developed.

A second and related issue is a pattern of different donor agencies replicating elements or entire projects and studies that had previously been undertaken by other agencies, adding little or nothing of substance. Several factors were noted to contribute to this repetition. One is a lack of bona fide collaboration among separate donor agencies: whilst there have indeed been examples of successful collaborative initiatives, participants noted that collaborative groups set up to cooperate on certain matters were not in reality meeting with each other. Competition between donor agencies was noted as a salient factor driving this pattern of behavior. Competition and repetition is arguably aided by a culture of secrecy in some quarters. For example, reports of communal value are not made publicly available and information concerning projects being developed is tightly guarded until ready to launch.

The final challenge posed by the relationship Fiji has with its donors is that it sometimes subverts the state from setting its own development priorities. The tendency for the state to tailor requests according to donor agendas was well documented and indeed these requests may not be consistent with Fiji's most pressing needs.

\subsection{Level 4: Unchangeable Characteristics}

The fourth level of analysis considers aspects of the climate financing challenge in the Pacific and in Fiji that set it apart from most other regions of the world. It will be argued that these barriers cannot be wholly overcome, and must be internalized into business and policy plans; in other words, the ongoing effects of L4 issues on projects must be reflected in responsive costing, design, planning and engagement. Here we suggest the appropriate response is not necessarily to overcome these issues, rather, to understand them so policy makers and private developers can better work with and accommodate to, rather than work against these unchangeable characteristics.

\subsubsection{Geography, Distance and Scale}

Fiji has a population of 884,887 , which inhabits approximately 110 of its 330 islands; it is one of the most remote countries in the world. Both population (representing potential customers) and the remote islands characteristic of Fiji translates to small-scale projects, which, some argue, are of limited interest to investors.

The challenge inherent in Fiji's geography is best illustrated by logistical difficulties in rural electrification. As noted by one respondent with experience in remote projects, getting to remote outer islands is the first logistical challenge. Given the heavy equipment required by technicians, remote islands can only be reached by sea and ferry schedules can be inconsistent and unreliable. Once on island, the infrastructure such as roads or ports can be very rudimentary, making the transportation of equipment to site a serious challenge. If these logistical challenges are not properly understood and accurately factored into costing, projects can blow out significantly. This highlights the importance of local companies being involved in project development and delivery. The remote location also causes serious operation and maintenance challenges; it is often unfeasible for technicians based in Suva to service remote systems due to the distance. Training local technicians from the community has been a solution which has had mixed results, including system failure due to the migration of local technicians, as well as challenges imbedded in the communities' social hierarchy which will be explored below. 


\subsubsection{Land and Culture}

Sustainable development infrastructure projects are contingent on acquiring rights to land. In Fiji, dealings with land are both sensitive and complex.

Fiji is comprised $6 \%$ of freehold lands, $4 \%$ of state lands and approximately $90 \%$ of iTaukei lands. iTaukei land is communally owned and governed by custom; ownership of these lands cannot be transferred to developers. Developers thus must obtain a lease to use iTaukei lands by negotiating with the iTaukei Land Trust Board (TLTB) which acts on behalf of the customary owners [39]. One participant in local government noted that this process could take approximately a year. These lengthy processes have reportedly caused some developers and even donors to attempt to subvert some of the necessary processes in order to expedite processes. This is often done by offering certain land owners further funds directly. Whilst this perhaps speeds up project initiation, the disregard for customary processes invariably leads to short project lifespans and ultimate failure.

Community engagement and inclusion in RE development is essential, especially given the 'inherent distributed nature of renewable energies, together with the modularity of those technologies, and the development of innovative business models and financial mechanisms, are factors triggering and facilitating a more active participation of citizens in grass root RE community projects' [40] (p. 47). However, the primary research shows a disconnect between the need for community acceptance and the rollout of both donor and private sector projects. As an example, the primary research found that there were instances of training being conducted in English, which beyond being futile in communities who have little English proficiency, was seen by local authorities as a sign of disrespect. As noted by one former energy official, "Training is often problematic because most of it is in English. It's not the local language so what do you expect."

This resonates with the conclusions drawn by Michalena and Hills 'the failure to put RE into a local context, to emphasize local resilience building and to move the rhetoric from a secular nature to one which encompasses the "sense of place" and spiritual-nature of traditional Pacific communities, all help to block further community engagement towards RE.' [23] (p. 350).

\subsubsection{Social Embeddedness of Commercial Endeavors and Public Policy}

Interviewees noted that business and 'deals' in Fiji are deeply socially imbedded; progress and agreement is based on social networks, on 'who you know.' Business in Fiji cannot be anonymous or faceless, it requires the building of interpersonal connections and trust, and this is true not only of the business community but also of public agencies. In this study, this status quo was referred to both positively, as a continuation of the communitarian values of Fiji, and negatively, as a barrier to transparency and accountability.

At its worst this social 'embeddedness' can be likened to the political clientelism described by Dornan which has, in Fiji's past, operated to both motivate and stymy reform in the energy sector [41]. It can indeed affect the independence of regulation.

\subsection{Analysing Complexity through Interlinkages}

The stratification of barriers, as was undertaken above, is the first step to understanding the landscape of complexity in Fijian climate finance; however, if the analysis were to conclude here it would leave one with an incomplete picture. The second aspect of mapping complexity looks at the interlinkages between barriers on different levels (see Figure 1). These interactions are significant for the following reasons. A tractable issue on L1 may be rendered less so by links with more entrenched issues. Furthermore, these interactions evidence the larger point that barriers to financing sustainable and climate aligned development cannot be fully understood in isolation, and that root challenges must also be accounted for. The following section will highlight the relational dynamics between barriers discussed above. 


\subsubsection{How L2 Entrenching the Lack of Supportive Policy (L1)}

As noted in L1, implementation failure with regard to roadmaps and policy recommendations remains a significant challenge in Fiji. Many consultants developing such deliverables expressed frustration, and sometimes dysphoria at this pattern of inaction. "There is no current national energy policy. The 2013 draft energy policy was a good one. There was a lot of time spent in public consultation and some great consultants put a lot of time in. And then-nothing happened with this policy. It just sat there. It was never endorsed by parliament. It was never implemented" (former energy official). Interviews reveal a disconnect between high-level ambitions such as those made during Fiji's COP23 presidency, and follow through, as evidenced by a failure to implement reforms requisite to meet agreed goals. To understand this disconnect, the L1 issue of policy alignment must be viewed in light of its links with other levels.

Reformative lethargy is in part rooted in government capacity challenges discussed in L2. The state lacks the resources, for the reasons stated previously, to implement much of the policy reform suggested. It also highlights the fact that policy support cannot simply occur at the design or development stage, such as through 'roadmapping'. Positive examples of efficient implementation and reform, such as the Green Bond Initiative, reflected external support not only in the reformative design process but also across the implementation phases.

As noted previously, Fiji's power utility, like most in the Pacific, is a powerful political force. Elements apparent in EFL's institutional culture, such as a recalcitrance towards both renewables and IPP involvement, have been manifest also in Fiji's new Electricity Act analysed in the previous section. Lacunae in supportive policy (L1), was perceived by stakeholders to be rooted in the utility's lack of commitment to Fiji's NDCs (L2): "the utility hasn't seen the benefit in it, so there is no progress. Take the lack of a PPA framework, if the utility wanted it, it would happen" (respondent, consultant).

\subsubsection{How Donor Dysfunction (L3) Entrenches Bureaucratic Capacity and Private Sector} Development (L2)

Donor dysfunction has the potential to weaken government capacity, which is a significant barrier to sustainable development outcomes. The requirement that the Fiji government not only meet the needs of its dispersed and remote populations, but also, at times, the overly burdensome requirements of its donor community, is a salient driver of the nation's capacity constraints. Donor requirements monopolize much of government resources, especially at the mid to higher levels. Beyond reporting and complying with each individual donor's slew of requirements, high level bureaucrats spent a large share of their time in a near constant parade of donor meetings. Indeed 'consultant fatigue' was a clear theme apparent in interviews. As one consultant noted: "There is fatigue. You send in consultants, you do roundtables. You say [to public officials] we're working on this. They aren't even interested, you're just another face on the conveyor belt. It's not in fact country driven, or focusing on investors-it's just geared towards aid". Another consultant noted that the influence of external donor partners has distorted the traditional functions of government; and the increasing outsourcing of various functions to consultants and donors has contributed to the fraying institutional knowledge within Fiji's public sector.

The primary research also revealed that private sector actors perceived that donor projects of a certain design displaced private sector investment and distorted the growth of certain sectors. Indeed, private sector participants note how certain public electrification programs have distorted the market by creating community expectations "Why would we pay for PV if we were going to get it for free?" (private sector respondent). For example, when remote systems were financed entirely publicly, it removed incentives to purchase systems or pay for their use. A positive response would be for the donor community to consider how their interventions could leverage and support private sector actors where appropriate. As noted by Michalena and Hill, the current status quo lacks organically grown sustainable opportunity: 'Development partners and financial support act as a prerequisite for RE progress rather than an auxiliary RE leverage tool.' [23] (p. 350). 
4.5.3. How Immutable Barriers of Geography Society and Culture (L4) Root Those in More Tractable Levels

Limited government capacity, for example, in part stems from immutable geographic factors. Capacity constraints are perpetuated by the challenges inherent in governing a nation comprised of small, dispersed and remote islands. The task of rural electrification, the purview of the Department of Energy, and the mixed results yielded thus far, illustrates this point. In some cases, the Department has taken years to respond to reports of solar home system malfunction, leaving homes reported to be 'electrified' in official statistics without power for inordinate periods. It is overly simplistic to cite negligence as the core of the issue when one considers the process and resource investment required in managing remote systems. Firstly, the repair request must be channeled from the outer islands to the administrative center. Once received and queued, a technician must be sent to diagnose the issue, and then later to administer a solution. Some islands are only accessible by ship, which have infrequent and unreliable schedules. Simply to identify the issue in one system a technician may need to commit months of human resources and expenses before they can consider the repairs, which may or may not be (depending on the ownership and maintenance model) fiscally feasible.

Geographical factors of scale also root the L2 challenge of underdeveloped private sector and limited energy market opportunity; the remote island characteristic as well as population of Fiji means that energy projects are small and often fragmented. That the inherently small scale of the energy market translates to limited commercial interest and avenues for competition is a common feature across Small Island Developing States globally [42]. In Fiji, rural electrification theoretically provides opportunity for private companies outside of EFL's monopoly. But logistically, the challenges inherent in the scale and distance have limited the ability for rural electrification to prove a profitable expansion of market opportunity. The research shows that the issue of land access (L4) also has affected the development of the private sector. It forms a crucial barrier to SMEs accessing finance, as land ownership is still required as collateral.

Both issues of social embeddedness and scale (discussed in L4) have impacts on regulatory functions. Dornan, for example, notes (citing Stern) that regulatory capture is a real risk in small countries under 3 million [35] (p. 322). This phenomenon plays out in both a community level and a national level. Participants noted this in the experience of training local technicians in a remote community for operation, maintenance and fee collection for electricity. Here, the trained individual was of a lower social standing in the community, and thus, by community standards could not demand payment from nor disconnect the power of higher-ranking individuals.

On a state level this phenomenon is also perceptible. In Fiji, the political, economic and social elite are closely connected and frequently interactive (L4), and this has consequences not only for regulatory integrity (L1), but also for the openness of opportunities for new participants, such as IPPs, as is evidenced in the energy sector (L2). Indeed, the tariff dysfunction noted by participants also reflects the core issue of regulatory challenges in small jurisdictions.

\subsection{Why Conceptualize the Climate Finance Challenge in Terms of Stratified Interlinking Barriers?}

The findings of this research demonstrate the climate financing challenge in Fiji is complex, and is made up of distinct barriers interlinking across levels of entrenchment (see Figure 1). Grasping and responding to this complexity is important; fractured and limited perspectives as to the nature of the challenge have unsurprisingly yielded mixed results in terms of outcomes and implementation.

The stratification of barriers is helpful for multiple reasons. L1 barriers are, prima facie, most tractable, whereas L4 consist of immovable limits with ascending levels of entrenchment between them. This delineation equips governors with tools to understand their agency by representing the structures which may constrain them. By delineating entrenchment, the framework has the potential to guide governors in assessing the feasibility of certain approaches. For example, programs that have worked in other regions such as Asia that rely on a thriving private sector and financial market infrastructure may not be translatable to Fiji in the short term, as these corresponding L2 barriers are 
reasonably entrenched. To provide another example, a financier may be looking to invest in rural electrification yet have failed to consider L4 factors, wrongly assuming that land negotiations and community engagement are processes which can be subverted or challenges which can be overcome. The frustration of these expectations may lead to a blowout of project costs or even to complete project failure.

Another benefit of the stratification framework is that it allows one to see at what level programs and support have been targeted at. As noted previously, respondents indicated that developmental support was concentrated at L1 which has been marred by significant repetition of outputs, such as roadmaps. It is indeed understandable that international development partners are engaging at L1 as the lack of supportive policy is one of the most present barriers stymying the uptake of renewables. However, the repeated failure (or at best, mixed results) of L1 initiatives to deliver intended policy outcomes suggests a level of policy myopia and a failure to learn from past experience. The difficulty many stakeholders have experienced in their attempts to ameliorate this L1 policy dysfunction becomes more explicable when one considers its roots: bureaucracy with limited capacity and often limited confidence to implement reforms, donor dysfunction, a politically influential utility as well as a climate of heightened influence of the social, political and economic elite all operate to entrench the challenge of aligning Fiji's policy towards its mitigation goals. As noted by Eisenack et al. 'understanding the interdependencies of barriers is central for explaining their occurrence, persistence and resolution.' [26] (p. 869). In short, engaging with barriers in isolation and overlooking complex interlinkages with other levels, generates widespread policy failure.

Policy myopia not only represents an inefficient use of public and developmental funds, but is also a waste of an equally precious resource in Fiji and the Pacific: time. Fiji's development has already been seriously affected by climate change, and the need for near-term, effective climate strategies is critical when facing this kind of challenge.

\section{Conclusions}

For Fiji to reach its emissions reduction target in the energy sector, approximately $\$ 2.97$ billion USD must be invested over the next eleven years. Yet, to effectively participate in financing climate related projects in Fiji, both public and private sector stakeholders must navigate various challenges. As this paper has demonstrated, distinct barriers of varying levels of entrenchment stand between the climate finance governor and climate outcomes. Beyond this, these barriers interlink, resulting in further entrenchment. The landscape through which finance must traverse to result in climate outcomes is complex.

Arguably, a failure to engage with complexity is a key factor in both unsuccessful attempts at attracting and effectively investing climate finance. Accordingly, through dedicated fieldwork, grounded and inductive research, this paper has aimed to foster a deeper understanding of the complexity of the climate financing challenge in Fiji. In so doing, this paper aims to provide governors with essential building blocks with which to formulate governance interventions that are not myopic to the complexity of challenges faced.

There are certain limitations to this study. Firstly, the analysis herein represents the barriers most represented in the data. This study does not purport to have been an exhaustive review. Secondly, the study omitted exploration of how barriers at the top of the pyramid exacerbate issues further down. Take for example, how a lack of regulatory incentives for IPPs (L1) maintain the status quo of an underdeveloped private sector and the exclusivity of energy market (L2). These were not included, as this type of thinking and analysis has already grounded much work in this space, including the proliferation of roadmaps and policy advice centered at L1. Another limitation is that this study has not explored how issues on the same level interact; for example, the close links between underdeveloped private sector (L2) and limited financial opportunity (L2).

A resonant theme in the research was the vital need for governors to respond to 'context.' But what is this context? Various contextual understandings can empower governors; indeed the 
barriers presented today add form to the nebulous space of the 'context' that is so vital to governors. The methods employed in delineating these barriers, of grounded inductive construction of knowledge, were key in doing so. This deeper understanding of barriers, generated from the empirics and the subsequent development of an analytical framework capable of encapsulating complexity, is a vital first step to exploring how these barriers may be responded to.

Such governance responses, however, must be left to a subsequent paper. The present study lays a foundation for this further research. Pressing questions to be explored include: how have Fijian governors successfully navigated this complex landscape of barriers? Can these successful governance responses be replicated, adapted or scaled?

Funding: This project was funded by the Australian Department of Foreign Affairs and Trade, Aid for Trade Division.

Acknowledgments: This paper forms part of the ANU Energy Change Institute's Grand Challenge to bring Zero-Carbon Energy to the Asia Pacific. I am very thankful for Gunningham, Setyowati, Downie and Nitschke for their insightful reviews and comments. I would also like to acknowledge the collegiality and generosity of the School of Government, Development and International Affairs at The University of the South Pacific, who supported me as a visiting scholar while I conducted this research. I am also deeply grateful to the stakeholders whose perspectives informed this research.

Conflicts of Interest: The author declare no conflict of interest

\section{References}

1. Bainimarama, F. Hon. Pm Bainimarama's Remarks for News Conference at the One Planet Summit; United Nations: New York, NY, USA, 2018.

2. Ministry of Economy, Republic of Fiji. Fiji NDC Implementation Roadmap 2017-2030; Ministry of Economy: Suva, Fiji, 2017.

3. Morgan, K.J.; Orloff, A.S. (Eds.) The Many Hands of the State: Theorizing Political Authority and Social Control; Cambridge University Press: Cambridge, UK, 2017; ISBN 978-1-316-47158-6.

4. Farrelly, T.; Nabobo-Baba, U. Talanoa as empathic apprenticeship: Talanoa as empathic apprenticeship. Asia Pac. Viewp. 2014, 55, 319-330. [CrossRef]

5. Fa'avae, D.; Jones, A.; Manu'atu, L. Talanoa'i 'A e Talanoa-Talking about Talanoa: Some dilemmas of a novice researcher. Altern. Int. J. Indig. Peoples 2016, 12, 138-150. [CrossRef]

6. Korstjens, I.; Moser, A. Series: Practical guidance to qualitative research. Part 2: Context, research questions and designs. Eur. J. Gen. Pract. 2017, 23, 274-279. [CrossRef]

7. Samuwai, J.; Hills, J. Assessing Climate Finance Readiness in the Asia-Pacific Region. Sustainability 2018, 10, 1192. [CrossRef]

8. Carrozza, I. Climate Finance in the Asia-Pacific: Trends and Innovative Approaches; United Nations Economic and Social Commission for Asia and the Pacific (ESCAP): Bangkok, Thailand, 2015.

9. UNEP Inquiry. Aligning the Financial Systems in the Asia Pacific Region to Sustainable Development; UNEP: Jakarta, Indonesia, 2015.

10. Mehta, A.; Sandhu, S.C.; Kinkead, B.; Teipelke, R. Catalyzing Green Finance: A Concept for Leveraging Blended Finance for Green Development; Asian Development Bank: Manila, Philippines, 2017.

11. Forstater, M.; Halle, M.; Zadek, S. Green Finance for Developing Countries: Needs, Concerns and Innovations; UNEP, 2016. Available online: http://unepinquiry.org/wp-content/uploads/2016/08/Green_Finance_for_ Developing_Countries.pdf (accessed on 1 December 2018).

12. Biswas, R. Mobilising Private Capital Flows for Infrastructure Development in Asia and the Pacific; ESCAP: Bangkok, Thailand, 2016.

13. Deutsche Gesellschaft für Internationale Zusammenarbeit (GIZ) GmbH. Financing Green Growth A Review of Green Financial Sector Policies in Emerging and Developing Economies; Deutsche Gesellschaft für Internationale Zusammenarbeit (GIZ) GmbH: Bonn, Germany, 2014.

14. Atteridge, A.; Canales, N. Climate Finance in the Pacific: An Overview of Flows to the Region's Small Island Developing States; SEI: Oaks, PA, USA, 2017.

15. Prasad, R.D.; Bansal, R.C.; Raturi, A. A review of Fiji's energy situation: Challenges and strategies as a small island developing state. Renew. Sustain. Energy Rev. 2017, 75, 278-292. [CrossRef] 
16. Dornan, M.; Jotzo, F. Renewable technologies and risk mitigation in small island developing states: Fiji's electricity sector. Renew. Sustain. Energy Rev. 2015, 48, 35-48. [CrossRef]

17. Sharma, K.; Ahmed, M.R. Wind energy resource assessment for the Fiji Islands: Kadavu Island and Suva Peninsula. Renew. Energy 2016, 89, 168-180. [CrossRef]

18. Michalena, E.; Hills, J.M. Renewable Energy Governance; Lecture Notes in Energy; Springer: London, UK, 2013; Volume 57.

19. Hills, J.M.; Michalena, E.; Chalvatzis, K.J. Innovative technology in the Pacific: Building resilience for vulnerable communities. Technol. Forecast. Soc. Chang. 2018, 129, 16-26. [CrossRef]

20. Dornan, M. Solar-based rural electrification policy design: The Renewable Energy Service Company (RESCO) model in Fiji. Renew. Energy 2011, 36, 797-803. [CrossRef]

21. Dornan, M. Access to electricity in Small Island Developing States of the Pacific: Issues and challenges. Renew. Sustain. Energy Rev. 2014, 31, 726-735. [CrossRef]

22. Timilsina, G.R.; Shah, K.U. Filling the gaps: Policy supports and interventions for scaling up renewable energy development in Small Island Developing States. Energy Policy 2016, 98, 653-662. [CrossRef]

23. Michalena, E.; Hills, J.M. Paths of renewable energy development in small island developing states of the South Pacific. Renew. Sustain. Energy Rev. 2018, 82, 343-352. [CrossRef]

24. Taibi, E.; Gualberti, G.; Bazilian, M.; Gielen, D. A framework for technology cooperation to accelerate the deployment of renewable energy in Pacific Island Countries. Energy Policy 2016, 98, 778-790. [CrossRef]

25. Keeley, A.R. Renewable Energy in Pacific Small Island Developing States: The role of international aid and the enabling environment from donor's perspectives. J. Clean. Prod. 2017, 146, 29-36. [CrossRef]

26. Eisenack, K.; Moser, S.C.; Hoffmann, E.; Klein, R.J.T.; Oberlack, C.; Pechan, A.; Rotter, M.; Termeer, C.J.A.M. Explaining and overcoming barriers to climate change adaptation. Nat. Clim Chang. 2014, 4, 867-872. [CrossRef]

27. Asian Development Bank. Sector Assessment (Summary): Energy, Country Partnership Strategy: Fiji, 2014-2018; Asian Development Bank: Mandaluyong, Philippines, Undated.

28. Prasad, R.D.; Raturi, A. Low carbon alternatives and their implications for Fiji's electricity sector. Util. Policy 2019, 56, 1-19. [CrossRef]

29. International Finance Corporation. A Guide to Investing in Renewable Electricity Generation in the Pacific; International Finance Corporation: Washington, DC, USA, 2018.

30. IT Power. Review of International Renewable Energy Support Mechanisms; IT Power: New Delhi, India, 2014.

31. Asian Development Bank. Re-Invigorating Private Sector Investment: A Private Sector Assessment for Fiji; Asian Development Bank: Manila, Philippines, 2013.

32. International Renewable Energy Agency. Fiji Renewable Readiness Assessment; International Renewable Energy Agency: Abu Dhabi, UAE, 2015.

33. Wolf, F.; Surroop, D.; Singh, A.; Leal, W. Energy access and security strategies in Small Island Developing States. Energy Policy 2016, 98, 663-673. [CrossRef]

34. Cole, P.; Banks, G. Renewable energy programmes in the South Pacific-Are these a solution to dependency? Energy Policy 2017, 110, 500-508. [CrossRef]

35. Dornan, M. When international 'best practice' is not: Power sector reform in small island states. In Handbook of Small States: Economic, Social and Environmental Issues; Routledge: London, UK, 2018.

36. Dornan, M. Renewable energy development in small island developing states of the Pacific. Resources 2015, 4, 490-506. [CrossRef]

37. Sovacool, B.K. The intermittency of wind, solar, and renewable electricity generators: Technical barrier or rhetorical excuse? Util. Policy 2009, 17, 288-296. [CrossRef]

38. Boussalis, C.; Coan, T.; Peiffer, C.; Walton, G. Trends in Complaints to the Fiji Independent Commission against Corruption, 2007-2014. Available online: http://devpolicy.org/publications/reports/Trends-in-complaints-toFICAC-2007-2014.pdf (accessed on 1 December 2018).

39. iTaukei Land Trust Board. Land Ownership in Fiji; iTaukei Land Trust Board: Suva, Fiji. Available online: https://www.tltb.com.fj/getattachment/Media/Brochures/Land-Ownership-in-Fiji-Booklet-(1).pdf. aspx?lang=en-US (accessed on 1 December 2018).

40. Lucas, H.; Fifita, S.; Talab, I.; Marschel, C.; Cabeza, L.F. Critical challenges and capacity building needs for renewable energy deployment in Pacific Small Island Developing States (Pacific SIDS). Renew. Energy 2017, 107, 42-52. [CrossRef] 
41. Dornan, M. Reform despite politics? The political economy of power sector reform in Fiji, 1996-2013. Energy Policy 2014, 67, 703-712. [CrossRef]

42. Dornan, M.; Shah, K.U. Energy policy, aid, and the development of renewable energy resources in Small Island Developing States. Energy Policy 2016, 98, 759-767. [CrossRef] 